LAWRENCE LIVERMORE N A T IO N A L LABORATORY

Derivation Of Probabilistic Damage Definitions From High Fidelity Deterministic Computations

Lara D. Leininger

November 17, 2004 
This document was prepared as an account of work sponsored by an agency of the United States Government. Neither the United States Government nor the University of California nor any of their employees, makes any warranty, express or implied, or assumes any legal liability or responsibility for the accuracy, completeness, or usefulness of any information, apparatus, product, or process disclosed, or represents that its use would not infringe privately owned rights. Reference herein to any specific commercial product, process, or service by trade name, trademark, manufacturer, or otherwise, does not necessarily constitute or imply its endorsement, recommendation, or favoring by the United States Government or the University of California. The views and opinions of authors expressed herein do not necessarily state or reflect those of the United States Government or the University of California, and shall not be used for advertising or product endorsement purposes.

This work was performed under the auspices of the U.S. Department of Energy by University of California, Lawrence Livermore National Laboratory under Contract W-7405-Eng-48. 


\title{
Derivation Of Probabilistic DAMAge DeFINITIONS From HIGH FIDELITY DETERMINISTIC COMPUTATIONS
}

\author{
Lara D. Leininger \\ Defense Systems Analysis Group, Engineering \\ Missiles and Nuclear Technology Section, NAI \\ Lawrence Livermore National Laboratory \\ Livermore, California, 94551
}

\begin{abstract}
This paper summarizes a methodology used by the Underground Analysis and Planning System (UGAPS) at Lawrence Livermore National Laboratory (LLNL) for the derivation of probabilistic damage curves for US Strategic Command (USSTRATCOM).

UGAPS uses high fidelity finite element and discrete element codes on the massively parallel supercomputers to predict damage to underground structures from military interdiction scenarios. These deterministic calculations can be riddled with uncertainty, especially when intelligence, the basis for this modeling, is uncertain. The technique presented here attempts to account for this uncertainty by bounding the problem with reasonable cases and using those bounding cases as a statistical sample. Probability of damage curves are computed and represented that account for uncertainty within the sample and enable the war planner to make informed decisions.

This work is flexible enough to incorporate any desired damage mechanism and can utilize the variety of finite element and discrete element codes within the national laboratory and government contractor community.
\end{abstract}

\subsection{INTRODUCTION AND BACKGROUND}

The Underground Analysis and Planning System (UGAPS) is a capability at Lawrence Livermore National Laboratory (LLNL) derived from the combination of ground shock, discrete element, and structural response modeling expertise. UGAPS is under contract to provide USSTRATCOM with high fidelity computational solutions on targets of interest, but the output from high fidelity finite element and discrete element analysis is deterministic in nature. In order to be compatible with STRATCOM's current 
probabilistic war planning system, UGAPS must develop a methodology to translate deterministic analysis into probabilistic curves.

The methodology presented here is complementary to the work being performed for the Improved Groundshock Vulnerability Number (IGVN) program, where the damage metrics are peak strain and percent (\%) tunnel closure.

\subsection{CAVEATS}

Presented here is a methodology to populate a statistical model with computational and experimental data. Much like the Monte Carlo technique, the model will improve with every additional data point that can be included. Data points include computational simulations as well as experimental data and lessons learned from the Tunnel Target Defeat ACTD. As such, this model accommodates computational uncertainty, intelligence uncertainty, and experimental validation.

Conversely, there exists a level of uncertainty from professional engineering judgment that is inserted during intelligence production and interpretation, as well as with the building of computational models. This uncertainty is difficult to bound, especially since UGAPS is the end user - not the producer - of intelligence data. Consequently, this uncertainty is not accounted for in the model presented here.

Further, this methodology assumes a "direct hit", thus, ignoring the Circular Error Probable (CEP) of a weapon. CEP uncertainty is a spatial phenomenon and is handled separately. Therefore, the STRATCOM planning metric, Damage Expectancy (DE) is the product of Probability of Severe Damage (PSD) as described in this paper, probability of getting within the CEP, and Probability of Arrival (PA) as defined by the weapon/delivery system reliability.

Destroyed: A damage level that renders the critical element to a smoking pile of rubble. [author's definition]

Severe Damage: A damage level that requires essentially complete reconstruction or replacement of one or more critical major elements of the target, plus major reconstruction repair, or replacement of associated structures or equipment before any function can be performed. Severe Damage precludes the use of the target for any functional purpose. [PVH]

Moderate Damage: A damage level that requires major repairs to one or more critical elements of the target, plus major reconstruction, repair, or replacement of associated structures or equipment before the designed function can be performed. Moderate damage precludes effective use of the target for its intended functional purpose. [PVH]

Light Damage: A damage level that does not significantly reduce the target's functional capability but requires some repairs to restore the target to complete usefulness. [PVH]

Functional Kill: A damage level that precipitates "a significant reduction in a [target's] capability to perform its military function for a militarily significant period of time" [DTRA]. Each critical element/node/structure has individual damage criteria and associated recuperation time. 
The first step in determining statistical methodologies for defeat is to establish clear and consistent definitions of defeat. These definitions should not be specific to either nuclear or non-nuclear global strike missions so that the methodology can be applied in the comparison of Global Strike options.

Fortunately, most of the relevant damage definitions exist and a complete set is created by a little historical literature search. These qualitative definitions are listed in Figure 1 (previous page).

Although the qualitative damage metrics get the model started, they do not lead to the final answer. It is necessary that the metrics in Figure 1 correspond to quantitative numbers that are also consistent and universal. These quantitative metrics now bridge the gap between the level of damage and the specific target and, once again, they should not be specific to either nuclear or non-nuclear Global Strike missions so that the methodology can be applied in the comparison of strike options.

Specific quantitative' metrics are defined by the military, and they are available in the Bomb Damage Assessment (BDA) Handbook. Figure 2 has two such definitions:

\begin{tabular}{|l|l|}
\hline $\begin{array}{l}\text { Buildings, \% of target element area } \\
\text { damaged, "collapse of the structural } \\
\text { framing members within steel of }\end{array}$ & $\begin{array}{l}\text { Bunkers, fraction of bunker roof/side } \\
\text { walls collapsed [BDA] }\end{array}$ \\
$\begin{array}{l}\text { concrete framed building is not } \\
\text { necessary to achieve the levels of } \\
\text { physical damage" [BDA] }\end{array}$ & $\begin{array}{l}\text {-DESTROYED: > 1/3 } \\
\text {-SEVERE DAMAGE: < 1/3 } \\
\text {-MODERATE DAMAGE: weapon } \\
\text {-DESTROYED: 75-100\% } \\
\text {-SEVERE DAMAGE: 45-75\% } \\
\text {-MODERATE DAMAGE: 15-45\% }\end{array}$ \\
\hline \multicolumn{2}{|l|}{ trivial shock arrival }
\end{tabular}

By means of comparison, if the QtDM for "Buildings" in Figure 2 were applied to the June 1996 Khobar Tower bombing in Saudi Arabia (Figure 3), the building is considered moderately damaged because less than $45 \%$ of the exterior walls and cladding were damaged. On the other hand, the World Trade Center Towers targeted on September 11, 2001 would be considered destroyed.

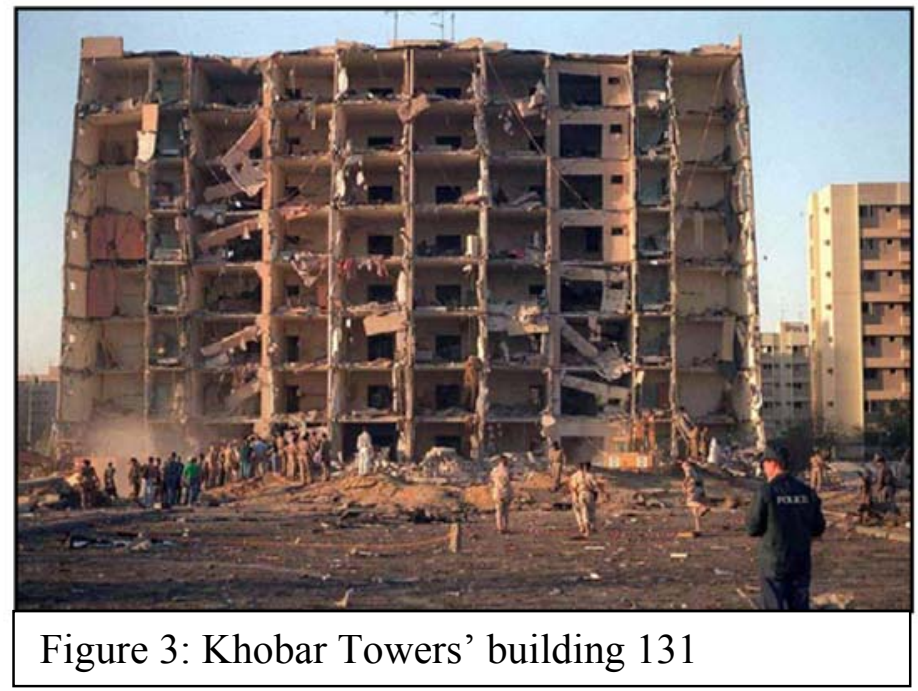


As previously mentioned, the BDA Handbook is being adopted here as the primary reference for QtDM. In this handbook, damage to a plethora of structures (including buildings and bunkers) is quantified for soldiers on the ground post-operation. The handbook specifically quantifies the total mass or volume fractions that have exceeded the yield strength of a material. In finite element constitutive models it is trivial to extract these fractions based on the evolution of plasticity variables after the initial yield strength is reached. A specific case study is presented in Figure 4.

Furthermore, this statistical methodology can use a combination of quantitative state variables to determine defeat. Some of these include relative volume (for bulking, combined with localized increases in nodal velocity could indicate spall), steel rebar strain (for plastic deformation and failure), and rubble volume (only for noncontinuum codes).

This methodology supports the user in the use of sound engineering professional judgment to select the appropriate damage metric (or combination of metrics) for the individual problem. It is imperative that the user exercise due diligence that the damage metric is appropriate and consistent (e.g. users must understand implications of using free field stress vs. free field strain or peak overpressure vs. peak impulse as a defeat criteria).

\section{Figure 4:}

Case Study: The Karigozian and Case concrete model implemented in DYNA3D [1]

- Concrete is of particular interest because of its ubiquity in underground structure construction.

- The Karigozian \& Case concrete model has a residual strength curve and parameter, $\delta$, that is equal to 1 when the concrete is on the yield surface (i.e. $\delta=1$ when $\sigma=\sigma_{y}$ ) and follows the evolution of the concrete hardening and softening under load.

- As a first data point, the percentage of concrete volume with $\delta>=1$, correlates directly to an aforementioned quantitative damage metric (QtDM).

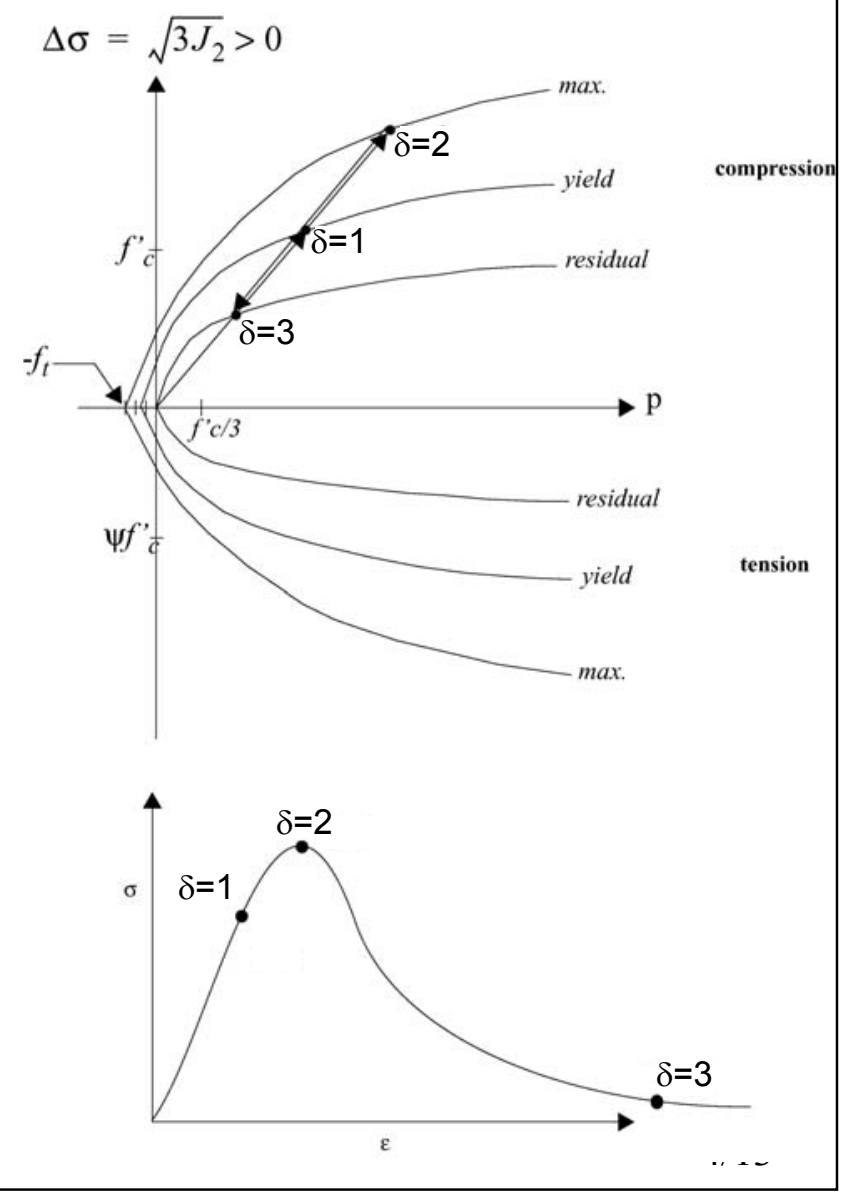


Probability of Damage (PD) is defined as the number of times a target is damaged to a specified level (i.e. Severe) divided by the number of shots fired at the target [2]. In this paradigm, the burst/source load remains the same and the target changes with a "population of targets with a hardness distribution specified by the VNTK" [2]. Furthermore, historical statistical analysis of Hiroshima and Nagasaki suggest that the damage expectancy will be log-normally distributed with the burst/source load for a given quantitative damage metric [3].

It is important to note that the PV Handbook leaves little ambiguity regarding the nature of damage expectancy and the relationship to target hardness uncertainty. It is clear that there is no spatial relationship within the target boundaries. That is, damage expectancy cannot come from a range of expectancies at different locations in a target footprint for a particular driver; it comes from a range of expectancies for the same footprint and the same driver, only because the hardness of a target has uncertainty associated with it.

\subsection{METHOdology: THE LOGNORMAL DISTRIBUTION}

Beginning with Hiroshima and Nagasaki historical data analysis [3] suggesting that the damage expectancy will be lognormally distributed with the burst/source load for a given quantitative damage metric, and using the quantitative damage metrics that have been itemized in the previous sections, the methodology characterization continues with lognormal distribution definitions.

When looking into the lognormal distribution, it is important to acknowledge the Central Limit Theorem of the Normal Distribution directs that a sample set should have $>30$ samples in order to be considered statistically significant. All analysis presented here should keep this factor close at hand: statistical interpretations to whole populations from sample sets are only as good as the quality (and relevance) of the sample size.

Assume that a quantity is lognormally distributed, $\Lambda\left(\mu, \sigma^{2}\right)$, where $\mu$ is the mean of the distribution and $\sigma$ is the standard deviation of the distribution and $\sigma^{2}$ is the variance of the distribution. Given experimental or computational data, the mean and standard deviation can be estimated, and subsequent scenarios can be predicted by interpolating along the curves defined by the estimation of the mean and standard deviation. The minimum variance unbiased estimators of $\mu$ and $\sigma^{2}$ are $m_{1}$ and $s_{1}^{2}$ respectively [4]. If $x_{i}$ are the observations, then from the Method of Maximum Likelihood: 


$$
\begin{aligned}
& y_{i}=\log x_{i} \\
& m_{1}=\bar{y}=\frac{1}{n} \sum_{1}^{n} y_{i} \\
& s_{1}{ }^{2}=v_{y}{ }^{2}=\frac{1}{n-1} \sum_{1}^{n}\left(y_{i}-\bar{y}\right)^{2}
\end{aligned}
$$

Furthermore, the mean and variance can be defined as the first and second derivative (respectively) of the moment of the distribution. Aitchison defines the $j^{\text {th }}$ moment for the lognormal distribution as:

$$
e^{j \mu+\frac{1}{2} j^{2} \sigma^{2}}
$$

Therefore:

$$
\begin{aligned}
& \alpha \equiv M_{1}(\text { mean })=e^{\mu+\frac{1}{2} \sigma^{2}} \\
& \beta^{2} \equiv M_{2}(\text { variance })=e^{2 \mu+\frac{1}{2} \sigma^{2}}
\end{aligned}
$$

Thus, the lognormal distribution can also be represented as $\Lambda\left(\alpha, \beta^{2}\right)$ which is a form that is seen frequently in Improved Groundshock Vulnerability (IGVN) literature. The parameters $\alpha$ and $\beta$ have corresponding minimum unbiased estimators of $a_{1}$ and $b_{1}^{2}$ that are significantly more complicated and will not be reprinted here.

To check the assumption that the lognormal distribution represents the available data, this methodology employs the Chi-Squared, $\chi^{2}$, Goodness of Fit test. The $\chi^{2}$ test establishes a confidence measure to determine if, indeed, the parameters calculated, and the resulting lognormal distribution, fit the actual data. In this test, a $\chi^{2}$ number is computed that relates the square of the differences between the actual frequency and the frequency predicted by the parent distribution (lognormal in this case). From Young [5]:

$$
\chi^{2}=\sum_{n} \frac{(N f(n)-F(n))^{2}}{N f(n)}
$$

Where $N$ is the number of classes, $f(n)$ is the probability density function predicted by the parent distribution, and $F(n)$ is the cumulative density function of the actual data.

Given the $\chi^{2}$ and the degrees of freedom, $v$, which is $(\mathrm{k}-1)$ [where $\mathrm{k}$ is the number of classes used in computing the $\left.\chi^{2}\right]$, a glance at the cumulative distribution of ChiSquare indicates the likelihood that the data "fits". Typical examples for 2 degrees-offreedom are $\chi^{2}=0.02$ for $99 \%$ confidence, $\chi^{2}=0.58$ for $75 \%$ confidence, and $\chi^{2}=1.39$ for $50 \%$ [6]. Modern statistical computation programs can calculate an exact confident percentage from $\chi^{2}$ and $v$.

\subsection{Application of Methodology to Hard Hat and Pile Driver}

The aforementioned methodology can now be applied to the community accepted benchmark tests: Hard Hat (HH) and Pile Driver (PiD). HH and PiD were nuclear tests 
conducted in granite at the Nevada Test site and they included underground structures of varying design and hardness. Each test had three radial drifts (intuitively named A, B, and $\mathrm{C}$ Drift) at varying distances away from the device. The tests were designed so that the letter drift in each test saw a similar side-on shock peak strength; therefore the $\mathrm{HH}$ and PiD tests could be lumped together and the structures in the test could be treated as "a population of targets with a hardness distribution" as directed by the PV Handbook. There is a significant amount of uncertainty regarding the actual shock strength and freefield stress in the drifts for these tests. The estimates from Alfred Hendron are used based on the recommendation of the Hard Rock Database Review (HRDR) final review [7] because all the relevant available estimates fit within A. Hendron's estimated range. Hendron's shock strength estimates at the three different drifts for the two tests are shown in Table 1. To normalize the data ranges from the two tests, an assumption was made that the data within the range is normally (Gaussian) distributed and that there is a $99 \%$ confidence interval that all the data falls within this range. Using statistical relationships for the Normal Distribution, the expected value (mean) is calculated and shown in Table 1. The expected value for each test is averaged to get three values for each drift and this number is used as the "burst/source load" for each of the drifts. That gives a shock magnitude of 1.3,3.2, and $6.9 \mathrm{kBar}$ for the $\mathrm{C}, \mathrm{B}$, and A drift respectively. To reiterate, with this methodology, the damage expectancy for the range of target hardness in each drift will be lognormally distributed.

Table 1: Hendron free field stress estimates (in kiloBar)

\begin{tabular}{|c|c|c|c|}
\hline Drift & $\begin{array}{c}\text { Bottom of } \\
\text { range }\end{array}$ & Top of range & $\begin{array}{c}\text { Expected Value } \\
(\mu)\end{array}$ \\
\hline \multicolumn{4}{|c|}{ Hard Hat } \\
\hline C & 0.5 & 2.0 & 1.25 \\
\hline B & 1.2 & 4.1 & 2.65 \\
\hline A & 2.6 & 9.0 & 5.80 \\
\hline \multicolumn{5}{|c|}{ Pile Driver } \\
\hline C & 0.6 & 2.2 & 1.4 \\
\hline B & 1.5 & 5.9 & 3.7 \\
\hline A & 3.4 & 12.4 & 7.9 \\
\hline
\end{tabular}

Tables 2, 3 and 4 call out the test and the state of damage as described in the literature [8] either: Destroyed (D), Severely Damaged (SD), Moderately Damaged (MD), or Lightly Damaged (LD). The heading of each table calls out the calculated Probability of Severe Damage (PSD) based on each data set. It is these PSD's, with the corresponding peak free-field stress, that will be fit to a lognormal parent distribution. 


\begin{tabular}{|c|c|}
\hline test/structure & damage \\
\hline HH A3a & D \\
\hline $\mathrm{HH}$ A3b & $\mathrm{D}$ \\
\hline $\mathrm{HH} A 3 \mathrm{c}$ & SD \\
\hline $\mathrm{HH}$ A3d & $\mathrm{D}$ \\
\hline $\mathrm{HH}$ A4a & D \\
\hline $\mathrm{HH} \mathrm{A4b}$ & D \\
\hline $\mathrm{HH} \mathrm{A} 4 \mathrm{c}$ & $\mathrm{D}$ \\
\hline $\mathrm{HH}$ A5a & D \\
\hline $\mathrm{HH}$ A5b & $\mathrm{D}$ \\
\hline $\mathrm{HH}$ A5c & $\mathrm{D}$ \\
\hline PD AR1 & $\mathrm{D}$ \\
\hline PD AR2 & $\mathrm{D}$ \\
\hline PD AR3 & $\mathrm{D}$ \\
\hline PD AR4 & D \\
\hline PD AR5 & $\mathrm{D}$ \\
\hline PD AR6 & $\mathrm{D}$ \\
\hline PD AR7 & $\mathrm{D}$ \\
\hline PD AR8 & D \\
\hline PD AR9 & D \\
\hline PD AR10 & $\mathrm{D}$ \\
\hline PD AR11 & $D$ \\
\hline PD AL1 & $\mathrm{D}$ \\
\hline PD AL2 & $\mathrm{D}$ \\
\hline PD AL3 & $\mathrm{D}$ \\
\hline PD AL4 & $\mathrm{D}$ \\
\hline PD AL5 & $\mathrm{D}$ \\
\hline PD AL6 & $\mathrm{D}$ \\
\hline PD AL7 & $\mathrm{D}$ \\
\hline PD AL8 & $\mathrm{D}$ \\
\hline PD AL9 & $\mathrm{D}$ \\
\hline PD AL10 & $\mathrm{D}$ \\
\hline PD AL11 & $\mathrm{D}$ \\
\hline PD AL12 & $\mathrm{D}$ \\
\hline PD AL13 & $\mathrm{D}$ \\
\hline PD AL14 & $\mathrm{D}$ \\
\hline PD AL15 & D \\
\hline
\end{tabular}

Table 3: drift B, 3.2 kbar, N=39, PSD 0.77

\begin{tabular}{|c|c|c|c|}
\hline test/structure & damage & test/structure & damage \\
\hline HH B2a & D & $\mathrm{HH}$ C2a & SD \\
\hline $\mathrm{HH}$ B2b & D & $\mathrm{HH}$ C2b & SD \\
\hline HH B3a & D & HH C3a & LD \\
\hline $\mathrm{HH}$ B3b & SD & $\mathrm{HH}$ C3b & LD \\
\hline HH B3c & LD & $\mathrm{HH}$ C3c & LD \\
\hline HH B3d & D & $\mathrm{HH}$ C3d & LD \\
\hline $\mathrm{HH}$ B4a & SD & $\mathrm{HH}$ C4a & LD \\
\hline $\mathrm{HH}$ B4b & SD & $\mathrm{HH}$ C4b & LD \\
\hline $\mathrm{HH}$ B4c & SD & $\mathrm{HH}$ C4c & LD \\
\hline HH B5a & $\mathrm{D}$ & $\mathrm{HH}$ C6a & LD \\
\hline $\mathrm{HH}$ B5b & SD & $\mathrm{HH}$ C6b & LD \\
\hline $\mathrm{HH}$ B5c & D & $\mathrm{HH}$ C6c & LD \\
\hline $\mathrm{HH}$ B6a & D & PD CR7 & LD \\
\hline $\mathrm{HH}$ B6b & SD & PD CR1 & LD \\
\hline $\mathrm{HH}$ B6c & D & PD CR1A & LD \\
\hline PD BL1 & D & PD CR2 & $\mathrm{D}$ \\
\hline PD BL2 & D & PD CR3 & LD \\
\hline PD BL3 & D & PD CR4 & MD \\
\hline PD BL4 & D & PD CR-T & MD \\
\hline
\end{tabular}

Combining all the data, and using the Method of Maximum Likelihood, the minimum variance unbiased estimators of $\mu$ and $\sigma^{2}$ are calculated $\left(m_{l}=0.6233\right.$ and $\left.s_{l}{ }^{2}=0.3739\right)$ and plotted in Figure 5. A Chi Squared $\left(\chi^{2}\right)$ Goodness of Fit test shows that the parameters fit within that of the Hendron estimates of Table 1 with a confidence of $98 \%$, the corresponding $\chi^{2}=0.04$. Once the parameters are fit, it is trivial to interpolate PSD's at other shock strengths. For this particular example, the shock strength required to produce a $\mathrm{PSD}=0.7$ is $2.3 \mathrm{kBar}$. 


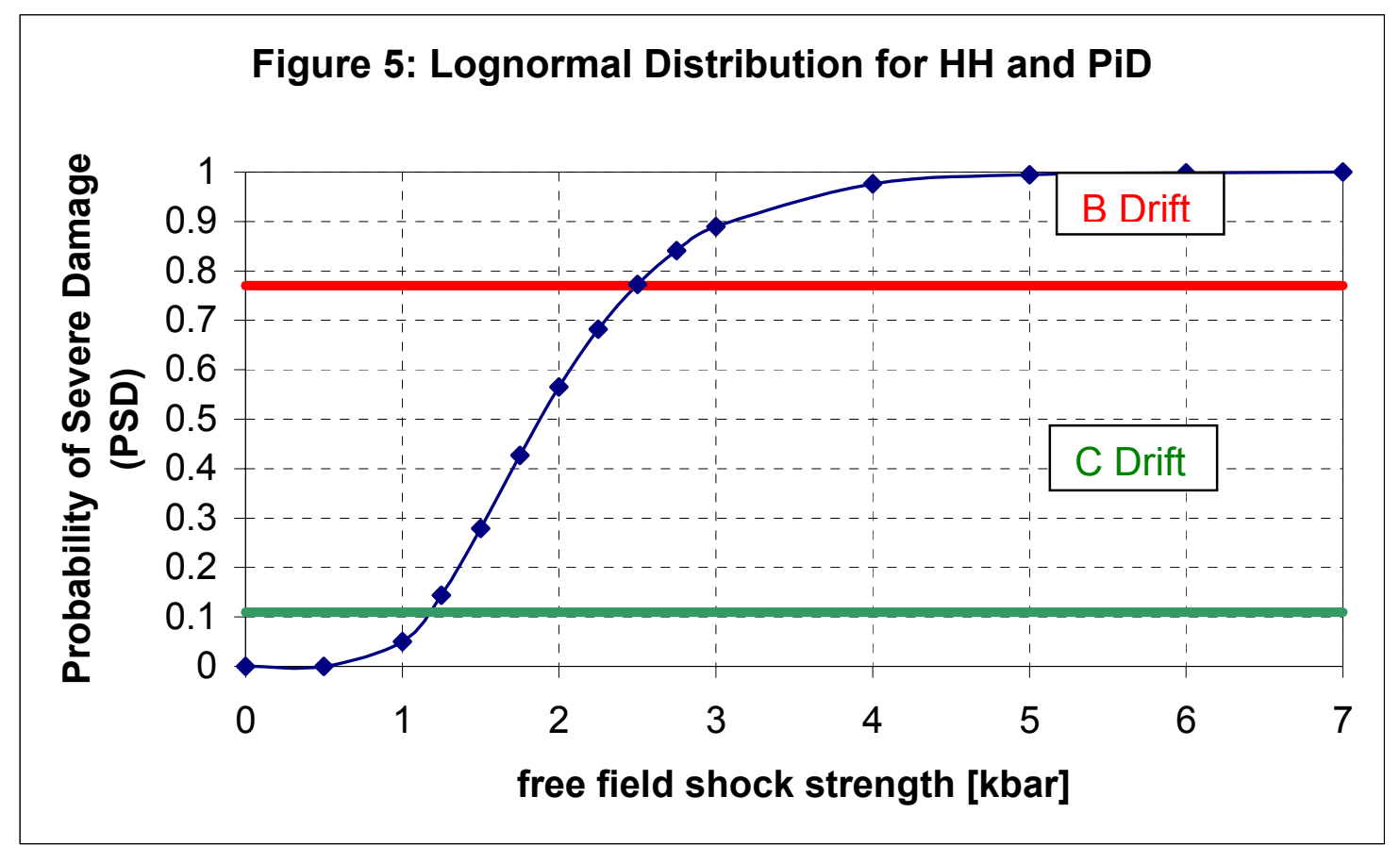

For the IGVN program, a series of finite element computations were performed to recreate tunnel closure seen in $\mathrm{HH}$ and $\mathrm{PiD}$ and to calculate \% peak closure for a subset of structures in these events. The IGVN community theorizes that the damage mechanism for tunnel defeat is peak strain (\% peak closure), NOT peak stress (kBar) as shown in Figure 5. Combining the data from IGVN with that of Tables $2,3 \& 4$, the same methodology can be applied to create damage curves based on \% peak (maximum) tunnel closure - for the same set of tests. That data is shown in Tables $6,7 \& 8$ (next page).

Below, in Table 5 the $\%$ peak closure data is "binned" by the $\%$ closure to create classes for fitting lognormal parameters.

Table 5: Data "bins" for HH and PiD

\begin{tabular}{|c|c|c|}
\hline Peak closure (\%) & PSD & \# data points supporting \\
\hline $\mathbf{0 . 5 - 1} \%$ & 0.375 & 8 \\
\hline $\mathbf{1 . 0 1 - 2} \%$ & 0.5 & 2 \\
\hline $\mathbf{2 . 0 1 - 3} \%$ & 0.5 & 6 \\
\hline $\mathbf{3 . 0 1 - 4} \%$ & .99 & 4 \\
\hline $\mathbf{4 . 0 1 - 5} \%$ & .99 & 1 \\
\hline $\mathbf{5 . 0 1 - 6} \%$ & $\mathrm{~N} / \mathrm{A}$ & 0 \\
\hline $\mathbf{6 . 0 1 - 7} \%$ & .99 & 1 \\
\hline $\mathbf{7 . 0 1 - 8} \%$ & .99 & 1 \\
\hline $\mathbf{8 . 0 1 - 9} \%$ & .99 & 2 \\
\hline $\mathbf{9 . 0 1 - 1 1 . 1} \%$ (and up) & .99 & 3 \\
\hline
\end{tabular}




\begin{tabular}{|c|c|c|}
\hline test/structure & $\begin{array}{c}\text { peak closure } \\
(\%)\end{array}$ & damage \\
\hline HH A3a & 4.2 & D \\
\hline $\mathrm{HH}$ A3b & & D \\
\hline $\mathrm{HH}$ A3c & & SD \\
\hline HH A3d & & D \\
\hline HH A4a & & D \\
\hline $\mathrm{HH}$ A4b & & D \\
\hline $\mathrm{HH}$ A4c & & D \\
\hline $\mathrm{HH}$ A5a & & D \\
\hline $\mathrm{HH}$ A5b & & D \\
\hline $\mathrm{HH}$ A5c & & D \\
\hline PD AR1 & 11.1 & D \\
\hline PD AR2 & 10.3 & D \\
\hline PD AR3 & & D \\
\hline PD AR4 & & D \\
\hline PD AR5 & 10.4 & D \\
\hline PD AR6 & & D \\
\hline PD AR7 & & D \\
\hline PD AR8 & & D \\
\hline PD AR9 & & D \\
\hline PD AR10 & & D \\
\hline PD AR11 & 3.7 & D \\
\hline PD AL1 & & D \\
\hline PD AL2 & & D \\
\hline PD AL3 & & D \\
\hline PD AL4 & & D \\
\hline PD AL5 & 8.8 & D \\
\hline PD AL6 & & D \\
\hline PD AL7 & & D \\
\hline PD AL8 & & D \\
\hline PD AL9 & 7.7 & D \\
\hline PD AL10 & & D \\
\hline PD AL11 & 6.9 & D \\
\hline PD AL12 & & D \\
\hline PD AL13 & 8.5 & $\mathrm{D}$ \\
\hline PD AL14 & & D \\
\hline PD AL15 & & D \\
\hline
\end{tabular}

Table 7: drift B, 3.2 kbar, $\mathrm{N}=39$

\begin{tabular}{|c|c|c|}
\hline test/structure & $\begin{array}{c}\text { peak } \\
\text { closure (\%) }\end{array}$ & damage \\
\hline $\mathrm{HH}$ B2a & 2.5 & $\mathrm{D}$ \\
\hline $\mathrm{HH}$ B2b & 2.5 & $\mathrm{D}$ \\
\hline $\mathrm{HH} \mathrm{B3a}$ & 1.5 & $\mathrm{D}$ \\
\hline $\mathrm{HH} \mathrm{B3b}$ & & SD \\
\hline $\mathrm{HH} \mathrm{B3c}$ & & LD \\
\hline $\mathrm{HH}$ B3d & & $\mathrm{D}$ \\
\hline $\mathrm{HH}$ B4a & & SD \\
\hline $\mathrm{HH}$ B4b & & SD \\
\hline $\mathrm{HH} \mathrm{B4c}$ & & SD \\
\hline HH B5a & & D \\
\hline $\mathrm{HH} \mathrm{B5b}$ & & SD \\
\hline $\mathrm{HH}$ B5c & & $\mathrm{D}$ \\
\hline $\mathrm{HH}$ B6a & & $\mathrm{D}$ \\
\hline $\mathrm{HH} \mathrm{B6b}$ & & SD \\
\hline $\mathrm{HH}$ B6c & & $\mathrm{D}$ \\
\hline PD BL1 & 3.4 & $\mathrm{D}$ \\
\hline PD BL2 & 3.2 & $\mathrm{D}$ \\
\hline PD BL3 & & $\mathrm{D}$ \\
\hline PD BL4 & 3.3 & $\mathrm{D}$ \\
\hline PD BL5 & & $\mathrm{D}$ \\
\hline PD BL6 & & $\mathrm{D}$ \\
\hline PD BL7 & & SD \\
\hline PD BL8 & & $\mathrm{D}$ \\
\hline PD BL9 & & SD \\
\hline PD BL10 & 1.6 & MD \\
\hline PD BR1 & & $\mathrm{D}$ \\
\hline PD BR2 & & $\mathrm{D}$ \\
\hline PD BR3 & & $\mathrm{D}$ \\
\hline PD BR4 & 2.9 & $\mathrm{D}$ \\
\hline PD BR5 & & $\mathrm{D}$ \\
\hline PD BR6 & & SD \\
\hline PD BR7 & & SD \\
\hline PD BR8 & 2.6 & LD \\
\hline PD BR9 & & LD \\
\hline PD BR10 & 2.5 & LD \\
\hline PD BR11 & & LD \\
\hline PD BR12 & 2.8 & LD \\
\hline PD BR13 & & LD \\
\hline PD BR14 & & LD \\
\hline
\end{tabular}

\begin{tabular}{|c|c|c|}
\hline \multicolumn{3}{|c|}{ Table 8: Drift C, 1.3 kbar, $\mathrm{N}=19$} \\
\hline test/structure & $\begin{array}{c}\text { peak closure } \\
(\%)\end{array}$ & damage \\
\hline $\mathrm{HH} \mathrm{C2a}$ & 0.8 & SD \\
\hline $\mathrm{HH} \mathrm{C} 2 \mathrm{~b}$ & 0.8 & SD \\
\hline $\mathrm{HH} \mathrm{C3a}$ & 0.6 & LD \\
\hline $\mathrm{HH} \mathrm{C3b}$ & & LD \\
\hline $\mathrm{HH} \mathrm{C3c}$ & & LD \\
\hline $\mathrm{HH}$ C3d & & LD \\
\hline $\mathrm{HH} \mathrm{C4a}$ & & LD \\
\hline $\mathrm{HH} \mathrm{C} 4 \mathrm{~b}$ & & LD \\
\hline $\mathrm{HH} \mathrm{C4c}$ & & LD \\
\hline $\mathrm{HH} \mathrm{C6a}$ & & LD \\
\hline $\mathrm{HH}$ C6b & & LD \\
\hline $\mathrm{HH} \mathrm{C6c}$ & & LD \\
\hline PD CR7 & 0.6 & LD \\
\hline PD CR1 & 0.9 & LD \\
\hline PD CR1A & & LD \\
\hline PD CR2 & 1 & $\mathrm{D}$ \\
\hline PD CR3 & 0.9 & LD \\
\hline PD CR4 & 0.9 & MD \\
\hline PD CR-T & & MD \\
\hline
\end{tabular}

The minimum variance unbiased estimators of $\mu$ and $\sigma^{2}$ are calculated to be $m_{1}=0.5913$ and $s_{1}^{2}=0.3739$, but unfortunately Chi Squared $\left(\chi^{2}\right)$ Goodness of Fit test shows that the parameters do not fit with the full set of data in Table 8. A closer inspection of the Goodness of Fit reveals that a high $\chi^{2}$ value is driven by the data under $1 \%$ peak closure. When that data was removed from the set, the lognormal distribution with the aforementioned estimators corresponded with $99.9 \%$ certainty. Therefore, this 
two-parameter estimation is perfectly valid (statistically speaking) for predictions above $1 \%$ peak closure.

Since the estimators form the Method of Maximum Likelihood do not create a distribution that fits all the data in this case, an alternative method is utilized to account for the tail of the data (under 1\%). A new set of estimators is created using a fixed value of the variance estimator, $b_{1}{ }^{2}$, and varying the median estimator, $\Delta D / D_{50}$, to match the data. This is the same one-parameter fit technique that is employed in the IGVN process and it is quite powerful for this case. The variance used in the IGVN program, based on US underground nuclear test data for tunnels is 0.4 [9]. Using $b_{1}{ }^{2}=0.4$, the $\Delta D / D_{50}$ value is calculated to be 0.9 and the correspondence with all the data improves to $99.9 \%$.

For example, if the planning factor for Probability of Severe Damage (PSD) is 0.7 or greater, the two techniques (two-parameter and one-parameter) predict a required closure of $2 \%$ and $1.3 \%$ respectively. Graphs of the two distributions are plotted in Figure 6. It is obvious that the two-parameter distribution is more conservative for warplanning applications where "good enough" is not "good enough" when nuclear weapons are being employed.

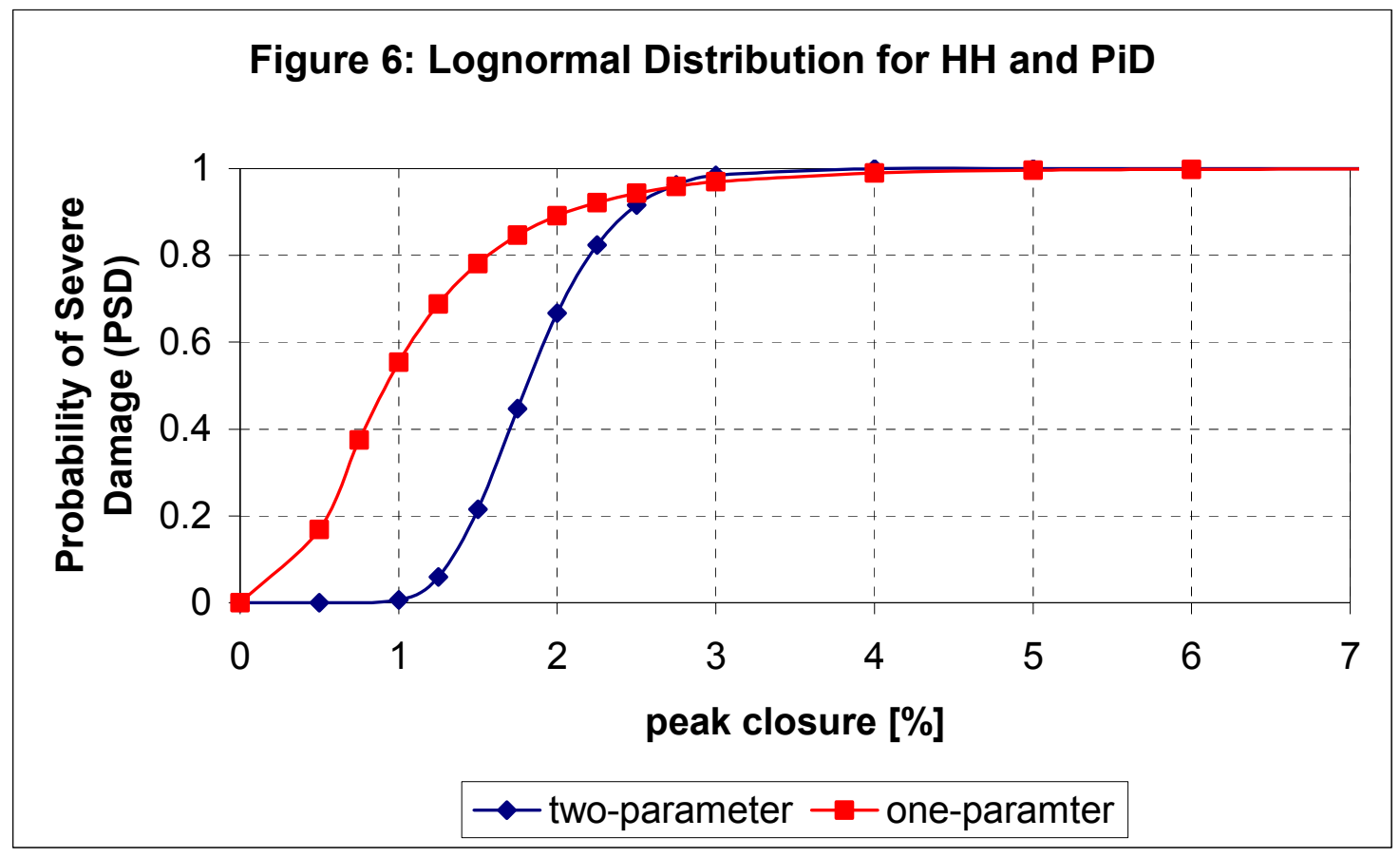

The emphasis of presenting two defeat mechanisms (peak stress and peak strain) is intended to demonstrate the flexibility of the methodology and the relevance of selecting a reasonable damage mechanism as well as doing statistical tests to check the Goodness of Fit of the lognormal distributions that will be used in the war-planning process. This is not a methodology that should be used blindly by the unintelligent or unobservant. The discussion of which damage mechanism is appropriate for this specific application will continue within the confines of the IGVN program. 


\subsection{COLLATERAL EFFECTS AND RECUPERATION TIME}

Every burst, source, or driver must have an associated collateral effect and recuperation time based on a Command-defined defeat objective and target footprint. Combining collateral damage, recuperation time, and probability of damage (severe, functional, etc.) - as outlined in this paper - is the only true way to enable a Commander to make educated Global Strike decisions.

Collateral effects and recuperation times are vital in the definition of combined nuclear and conventional scenarios that are required under the Global Strike mission. Recuperation time is the time after an attack during which a target cannot perform its original mission. It has been less relevant in low-fidelity, high volume, attack planning scenarios where the Damage Level Required (DLR) is severe or greater and the number of targets is enormous. The recuperation time for destroyed or severe damage mechanisms require complete reconstruction so recuperation time is long after conflict, but for lighter DLR (i.e., a functional kill that might be required because the collateral effects are unacceptable), recuperation time is for a "military significant period of time" as defined by the Commander. This can be hours, days, or months.

\subsection{CONCLUSION}

This paper has laid out a robust methodology for calculating the probabilities of damage from field and computational data. It is flexible enough to be used for varied damage mechanisms (from functional and light damage to severe damage) and it is this flexibility that will enable the Global Strike planning process. As UGAPS evolves and creates a database of high fidelity simulations for defeat for a variety of targets, these targets can be mixed and matched to provide a distribution of targets to encompass uncertainty on new threats where detailed structural data are not available. As such, the methodology described here becomes more robust as data is produced to populate statistical models and UGAPS becomes a more powerful planning tool.

Finally, it is essential to reiterate that the PD's defined here are only one piece of a larger Global Strike Planning puzzle that accounts for missions when the damage objective could be something other than a smoking hole and collateral effects and recuperation time are significant. It is the combination of collateral effects, recuperation time, and probabilities of damage that create the complete planning symphony. 


\section{REFERENCES}

[1] Malvar, L. J. and D. Simons, "Concrete Material Modeling in Explicit Computations"

[2] (C/NSI) "Physical Vulnerability Handbook for Nuclear Weapons (U)", DIA OGA-2800-23-92, I-10-11.

[3] Lulegian and Associates, "Statistical Analysis of Japanese Structural Damage Data", DNA4213F, January 1977.

[4] Aitchison, J. and J. A. C. Brown, The Lognormal Distribution, Cambridge at the University Press: London (1957).

[5] Young, Hugh D., Statistical Treatment of Experimental Data, McGraw Hill Book Company: New York (1962).

[6] Snedecor, George W. and William G. Cochran, Statistical Methods, Sixth Ed., The Iowa State University Press: Ames, Iowa (1967).

[7] "Hard Rock Database Review (HRDR) Final Report”, DTRIAC-SR-03-001-V1, July 2003.

[8] Burgess, D. N., "Final Report for Task 6: Response of Tunnels in HARD HAT and PILE DRIVER", Hard Rock Database Review (HRDR) Final Report, September 2002.

[9] "IGVN: A Report Detailing Improvements to the Calculation of the Groundshock Vulnerability Number", DRAFT FOR REVIEW, July 18, 2003. 